\title{
Assessing the Reliable Size of Distributed Energy Resources in Islanded Microgrid Considering Uncertainty
}

\author{
F. Tooryan, S. M. Moghaddas-tafreshi, S. M. Bathaee, and H. Hassanzadehfard
}

\begin{abstract}
Distributed energy resources have enormous potential and can meet the present world energy demand. The aim of this paper is minimization of net present cost of microgrid which involves investments, replacement, and operation and maintenance over its 20 years of operation. Prices are all empirical and components are commercially available. The microgrid considered in this paper consists of wind turbine (WT), photovoltaic array (PV), micro turbine (MT) and battery storage. A Particle Swarm Optimization algorithm is used to solve the optimization problem. System planning based on stipulated reliability criteria leads to robust architectures which can meet the consumers' requirements. This paper presents a method for determining sizing of resources from the available types of DER. Reliability is a measure of the system's capability to serve the demand. There are various indices which quantify the reliability of a micro grid system. Since the wind is unstable and variable energy source, and behave far differently than conventional sources, in this paper, we consider that effect as uncertainty on optimal size of WT. At last, a simulation result shows the effectiveness of the suggested microgrid.
\end{abstract}

Index Terms - Distributed energy resources, particle swarm optimization, reliability, uncertainty.

\section{INTRODUCTION}

The face of electricity generation and transmission are changed with countless incentives. Therefore, distributed energy resources (DER) have been receiving increasing attention over the past decade considerably as alternatives to centralized generation [1]. Those dispersed generations can be wind turbine, fuel cell, photovoltaic system, micro turbine with related power up to a hundred KW. A better way to realize the emerging potential of DG is a subsystem called microgrid which is predicted to play an increasing role in future power systems [2]. Microgrids which operate both electrical generation and loads in coordinated manner can offer as power additional benefits to the customer[3] such improving service reliability and better quality in addition to lower costs for providing uninterruptible power supply functions[4-5]. The use of different energy sources allows improving the system efficiency and the reliability of the energy supply and reduces the energy storage requirements compared to systems comprising only one single renewable energy source [6]. Therefore the micro-grid considered in this paper consists of a wind turbine, a photovoltaic array and battery storage. The research work presented in this paper is

Manuscript received May 25, 2012; revised August 23, 2012.

The authors are with the Electrical Engineering Department, K.N.Toosi University of Technology, Tehran, Iran (e-mail: f.tooryan@ sina.kntu.ac.ir, tafreshi@eetd.kntu.ac.ir, bathaee@eetd.kntu.ac.ir). focused on Finding optimal size of distributed generations in addition to some notions of reliability are considered for microgrid, and the effect of reliability on total cost of microgrid is evaluated. The optimization is carried out using particle swarm optimization (PSO) algorithms. PSO is one the evolutionary computational techniques It was developed through simulation of a simplified social system and has been found to be robust in solving continuous, nonlinear as well as discrete optimization problems. The PSO technique can generate high quality solution within shorter calculation time and has more stable convergence characteristics than other stochastic methods [7]. The concepts presented and simulation results illustrated in this paper show the beneficial of the methodology.

\section{PROBlem Formulation}

\section{A. Wind Turbine}

The following model used to calculate the power of the WT as a function of the wind velocity by Ref [8]:

$$
\left\{\begin{array}{l}
0 \quad V<V_{\text {cut-in }}, V>V_{\text {cut-off }} \\
P_{\text {rated }} \times\left(\left(V-V_{\text {cut-in }}\right) /\left(V_{\text {rated }}-V_{\text {cut-in }}\right)\right)^{3} \quad V_{\text {cut-in }} \leq V<V_{\text {rated }} \\
P_{\text {rated }} \\
V_{\text {rated }} \leq V \leq V_{\text {cut } \text {-off }}
\end{array}\right.
$$

where $P_{\text {rated }}$ is the rated Power, $V_{\text {cut-in }}$ cut-in and $V_{\text {cut-off }}$ cut-off wind speed respectively.

Furthermore, $V_{\text {rated }}$ and $V$ are the rated and actual wind speed.

\section{B. PV array}

In this paper, one simplified model applicable to the power output of PV array is used. This model shows the characteristics of PV in operating conditions which is differ from the standard condition [9].

$$
P_{P V}=P_{S T C} * G^{\prime} * \eta
$$

where $P_{S T C}$ is the power produced by $\mathrm{PV}$ in standard condition $\left(T=25^{0 \mathrm{C}}, G_{S T C}=1000\left(\mathrm{w} / \mathrm{m}^{2}\right)\right), \eta$ is PV efficiency and $G^{\prime}$ is the irradiation normalized with standard irradiation $G_{S T C}$.

$$
G^{\prime}=G / G_{\text {STC }}
$$

\section{Battery}

The battery capacity can be computed during the simulation. Since, the model depends on the pervious state of battery storage, the PV, WT energy production and load 
requirements. The power from the battery is needed whenever the PV and WT are insufficient to apply the load. On the other hand, the energy is stored whenever the supply from renewable sources exceeds the demand [6], [9], [10].

For battery, it is possible to contain negative energy so in this paper, we considered the maximum state of charge $\left(E_{\text {batmax }}\right)$ and minimum state $\left(E_{\text {batmin }}\right)$ of the battery which are $100 \%$ and $20 \%$ of its capacity respectively. The minimum allowable capacity can be determined by (4).

$$
E_{\text {batmin }}=(1-\mathrm{DOD}) E_{\text {batmax }}
$$

where DOD (\%) represents the maximum allowable depth of battery discharge.

\section{MOdELING OF SYSTEM}

The microgrid architecture studied is shown in Fig. 1. As mentioned before, micro-grid system which is investigated in this work is comprised PV, WT, MT and battery storage for balancing power produced and demand in the system.

\section{PROBLEM SOLUTION}

We choose net present cost for calculating the cost of microgrid. The objective function must be minimized and can be calculated as follows for each component [6].

$$
N P C=\left(I_{C}+M_{C}+R_{C}+O_{C}\right)
$$

where IC is the investment cost of units, $\mathrm{MC}$ is the present value of system life of maintenance costs, $\mathrm{RC}$ is the present value of the replacement of parts of the installation costs and $\mathrm{OC}$ is the present value of operation cost of MT, which are calculated as follows:

$$
C_{m}=\text { maintenance cost } \times 1 / \mathrm{CRF}(\mathrm{ir}, R)
$$

$$
C R F(i r, R)=\frac{i r(1+i r)^{R}}{(1+i r)^{R}-1}
$$

$$
R_{C}=\text { replacement }-\cos t * \sum_{n=1}^{Y} \frac{1}{(1+i r)^{L^{*} n}}
$$

$$
O_{C}=\left(F C \times F E \times A D G_{i}\right) \times C R F(\text { ir }, R)
$$

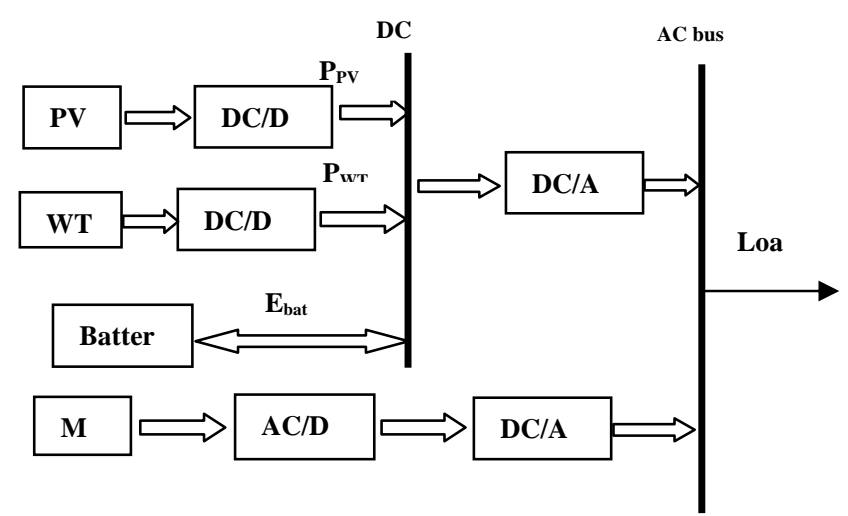

Fig. 1. Microgrid architecture

where $L$ is the lifetime, $N$ is the optimal number of each component, FC is the fuel cost, FE is heat efficiency of fuel and $\mathrm{ADG}_{\mathrm{i}}$ is the annual output power of ith micro-turbine.

\section{Simulation TechniQue}

Particle swarm optimization was introduced in 1995 by Kennedy (social psychology) and eberhart (electrical engineer). PSO technique conducts search using a population of particles corresponding to individuals as a potential solution to a problem, having $\mathrm{N}$-dimensional space with a memory of the previous best position as well as the best position among all particles in addition to a velocity component. At each iteration the particles adjusted their velocity along each dimension, which gives the new particle position. Updating of each dimension is independent [5], [8], [11]. PSO algorithm is faster and less complicated than other methods. In this study we assumed following PSO data: Population size: 30, Acceleration constants: $C 1, C 2=2$, Generation iteration: 500, Inertia weigh factor: $w=0.7$.

\section{Simulation RESUlts}

The optimal number of units ensuring that 20-year round total cost is minimized subject to the constraint that the load energy requirements are completely covered. Fig. 1 shows the load curve which is actually an IEEE standard curve with $750 \mathrm{~kW}$ peak, the yearly wind speed and solar irradiation are shown in Fig. 2 and Fig.3. For the sake of simplicity, we have considered the weekly mean in input data in our simulation. The data is the wind velocity and the demand in every one hour in a day. So, an average of the input data in each hour is calculated during a week.

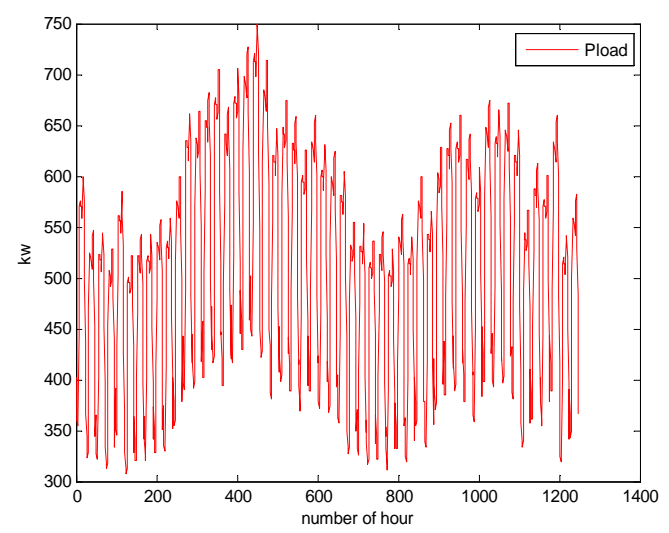

Fig. 2. Load curve.

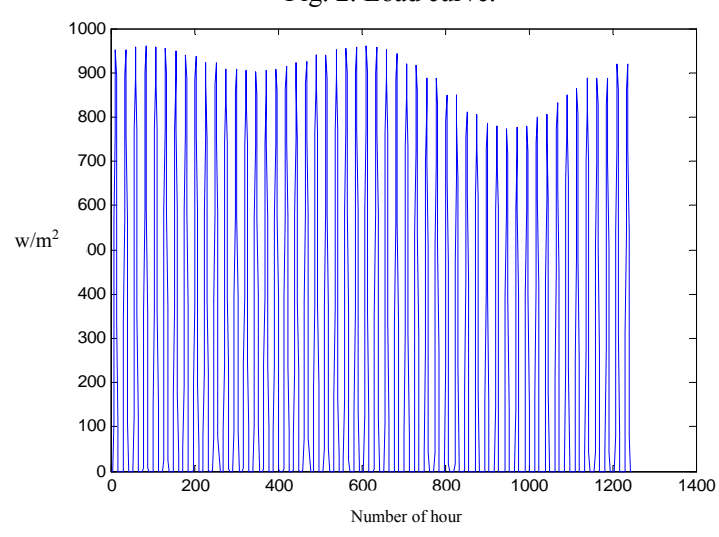

Fig. 3. Solar irradiation. 


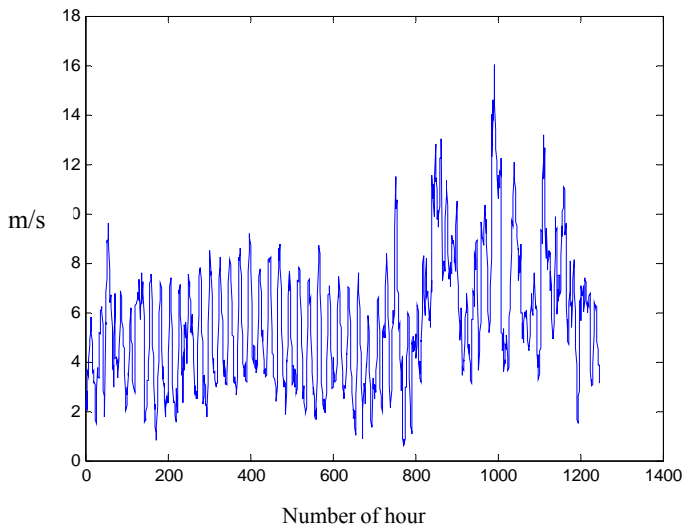

Fig. 4. Wind speed.

The optimum sizes of units which are used in this study are shown in Table I.

\begin{tabular}{ccccc}
\multicolumn{5}{c}{ TABLE I: OPTIMAL SIZE OF EACH COMPONENT } \\
\hline \hline $\begin{array}{c}\text { Number } \\
\text { Wind turbine }\end{array}$ & $\begin{array}{c}\text { Number } \\
\text { PV array }\end{array}$ & $\begin{array}{c}\text { Number } \\
\text { Battery } \\
\text { bank }\end{array}$ & $\begin{array}{c}\text { Number } \\
\text { Micro-turbin }\end{array}$ & $\begin{array}{c}\text { Cost } \\
(\$)\end{array}$ \\
\hline 2211 & 1675 & 510 & 25 & $2.6677^{*} 10^{7}$ \\
\hline \hline
\end{tabular}

Fig. 5-7. show the output power of wind turbine, PV array, micro turbine and fig. 8 shows energy of battery storages.

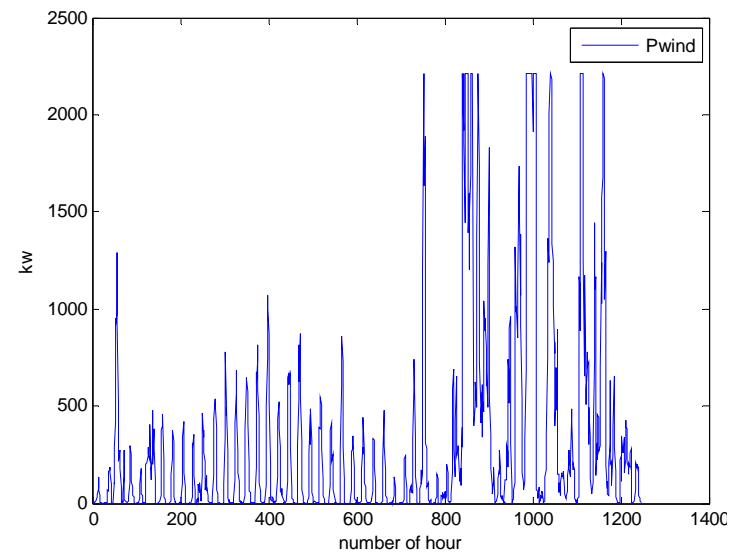

Fig. 5. Output power of wind turbine.

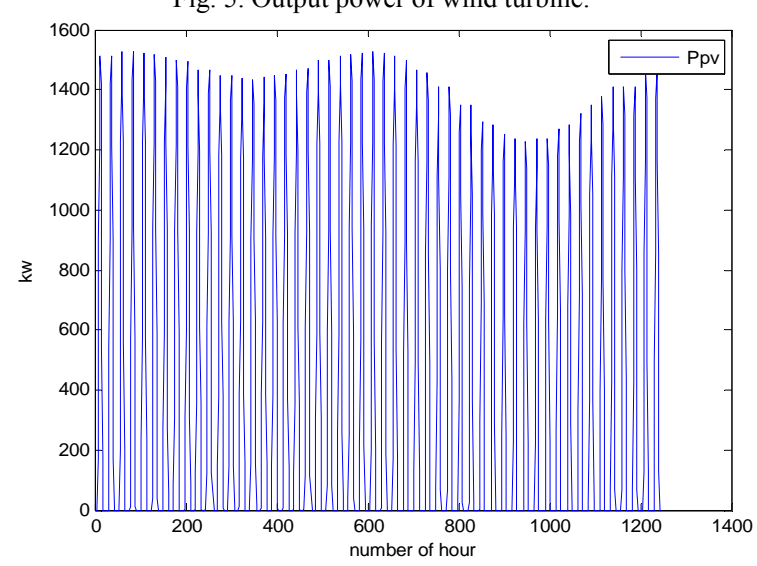

Fig. 6. Output power of PV array

We see that at the time between 200-700, micro turbine injects power to the micro-grid. Where the available battery storage energy is equal to minimum allowable storage capacity also output power of wind turbine and PV arrays do not satisfy the micro-grid's demand, so micro turbine injects power to the micro-grid in order to compensate load requirements.

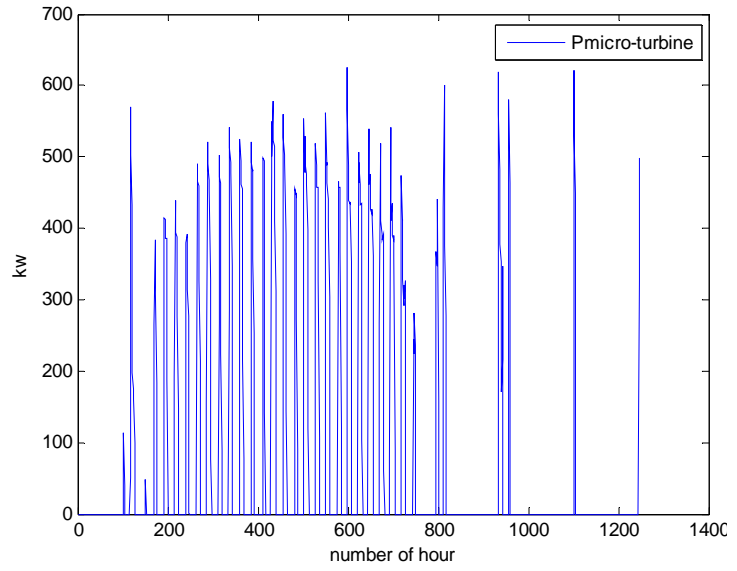

Fig. 7. Output power of micro-turbine.

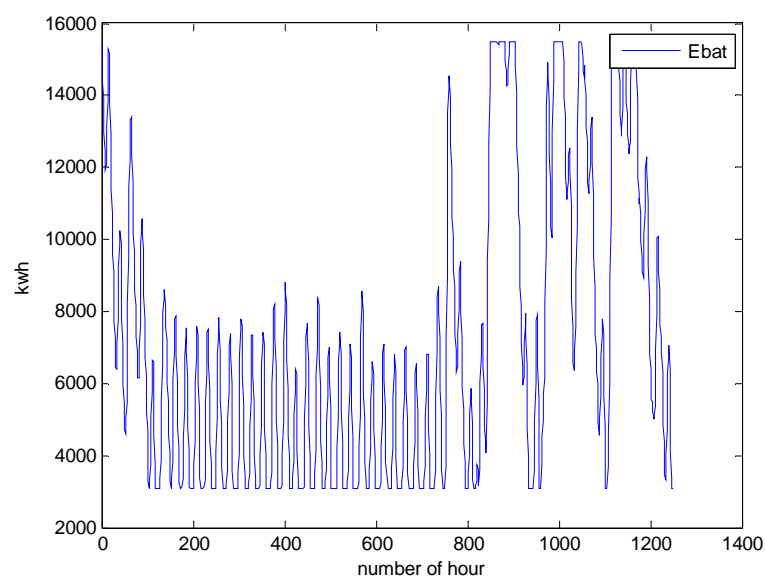

Fig. 8. Energy of battery storage.

\section{SuPply RELIABILITY EVALUATION INDICES}

Microgrid targeted in this study is independent area which serves its own power demand by the units. For a supply reliability index, we propose to use the two basic probabilistic indices which are the loss of load expectation (LOLE) and the loss of energy expectation (LOEE). LOEE is normalized with local energy demand and with peak load therefore we obtain the energy index of unavailability (EIU) and system minutes (SMs) [12].

The optimum sizes of units which are used in this study with considering reliability and are shown in Table II. The reliability indices of microgrids are shown in Table III. In this paper, the reliability constrain is LOLE must be less than 24 hours per year.

TABLE II: OPTIMAL SIZE OF EACH COMPONENT

\begin{tabular}{ccccc}
\hline \hline $\begin{array}{c}\text { Number } \\
\text { Wind turbine }\end{array}$ & $\begin{array}{c}\text { Number } \\
\text { PV array }\end{array}$ & $\begin{array}{c}\text { Number } \\
\text { Battery } \\
\text { bank }\end{array}$ & $\begin{array}{c}\text { Number } \\
\text { Micro-turbin }\end{array}$ & $\begin{array}{c}\text { Cost } \\
(\$)\end{array}$ \\
\hline 1377 & 1695 & 142 & 25 & $1.966^{*} 10^{7}$ \\
\hline \hline
\end{tabular}

TABLE III: THE RELIABILITY INDICES OF MICROGRIDS

\begin{tabular}{cccc}
\hline \hline LOLE (hr/yr) & LOEE (MWh/yr) & EIU (\%) & SM \\
\hline 24 & 1.658 & 0.26 & 132.656 \\
\hline \hline
\end{tabular}

From the results presented in Table II and Table III, it is concluded that the total cost of microgrids is decreasing when we consider the reliability indices. Table III shows that 
LOLE is in the acceptable confine.

\section{UNCERTAINTY OF WIND TURBINES}

For a long-term operation of a wind farm, the wind power forecast error is likely normally distributed [13].

To reduce the risk of incorporating uncertain wind forecast, the forecasting error can be estimated with a level of confidence. The error of wind generation forecast will be referred to as Wind-Gen at Risk [14].

Eq. (9) and (10) show a one-sided upper level of error approximation with $(100-\alpha) \%$ confidence interval for a normal distribution.

$$
\begin{gathered}
P\left[e-\mu_{e} \geq z_{\alpha} \sigma_{e}\right]=\frac{\alpha}{100} \\
e^{\sim}=\mu_{e}+z_{\alpha} \sigma_{e}
\end{gathered}
$$

where

\section{$e^{\sim}$ Wind-Gen at risk}

$\mu_{e}$ Mean value of the wind forecast error

$\sigma_{e}$ Standard deviation of the wind forecast error

In this paper we use three confidence levels such as $90 \%$, $95 \%$ and $99 \%$. The value of $z_{\alpha}$ is given in Table IV.

TABLE IV: ONE-SIDED UPPER STANDARD NORMAL DISTRIBUTION.

\begin{tabular}{cc}
\hline \hline$z_{\alpha}$ & $P\left[e-\mu_{e} \geq z_{\alpha} \sigma_{e}\right]$ \\
\hline 1.285 & $90 \%$ \\
1.645 & $95 \%$ \\
2.329 & $99 \%$ \\
\hline \hline
\end{tabular}

In this study we assume that $\mu_{e}$ and $\sigma_{e}$ are equal to $10 \%$ and $5 \%$ respectively.

Fig. 9 shows wind speed at different confidence levels in 24 hours.

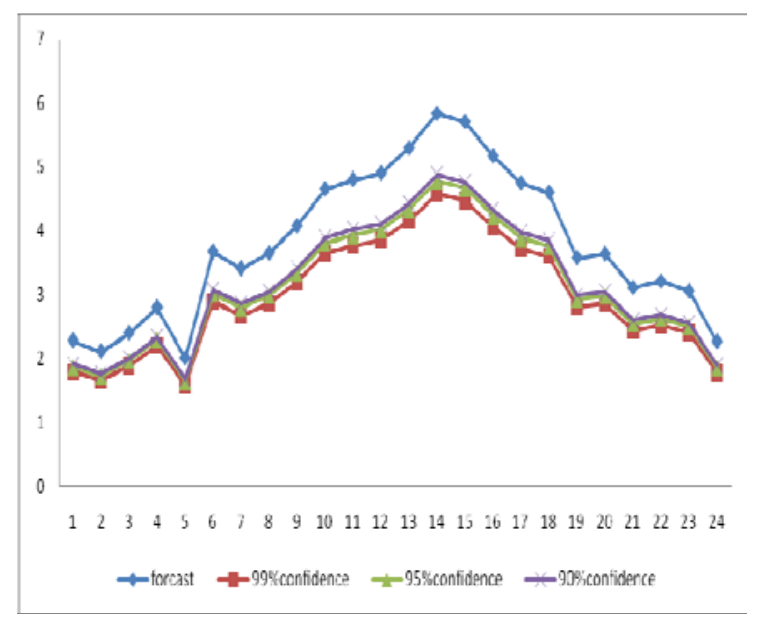

Fig. 9. Wind speed $(\mathrm{m} / \mathrm{s})$ at different confidence levels.

Table V shows optimal size of each component with three confidences level.

Table $\mathrm{V}$ shows that considering uncertainty for wind turbines causes total cost of micro-grid to increase but gives more assurance to system operators.
TABLE V: OPTIMAL SIZE OF EACH COMPONENT.

\begin{tabular}{cccccc}
\hline $\begin{array}{c}\text { Confidence } \\
\text { level }\end{array}$ & $\begin{array}{c}\text { Number } \\
\text { Wind } \\
\text { turbine }\end{array}$ & $\begin{array}{c}\text { Number } \\
\text { PV array }\end{array}$ & $\begin{array}{c}\text { Number } \\
\text { Battery } \\
\text { bank }\end{array}$ & $\begin{array}{c}\text { Number } \\
\text { Micro-turbir }\end{array}$ & $\begin{array}{c}\text { Cost } \\
(\$)\end{array}$ \\
\hline $90 \%$ & 233 & 2853 & 203 & 25 & $2.688 * 10^{7}$ \\
$95 \%$ & 263 & 2860 & 204 & 26 & $2.700^{*} 10^{7}$ \\
$99 \%$ & 400 & 2840 & 200 & 24 & $2.720^{*} 10^{7}$ \\
\hline
\end{tabular}

\section{CONCLUSION}

This paper presents a particle swarm optimization (PSO) approach to find the optimum size of micro-grid which is aimed at minimizing the cost function of the system.

In this paper we use the two basic probabilistic indices. It is concluded that the total cost of microgrids is decreasing when we consider the reliability indices. Also we consider uncertainty for wind generation and three confidence levels are assumed. When higher confidence level is selected the total cost of micro-grid increases but gives more assurance to system operators.

\section{REFERENCES}

[1] P. Costa and M. A. Matos, "Assesing the contribution of microgrids to the reliabilty of distribution networks," Electric Power Systems Research, vol. 79, pp. 382-389, 2009.

[2] F. A. Mohamed, H. N. Koivo, "System modelling and online optimal management of microgrid using multiobjective optimization," Clean Electrical Power, pp. 143-153, 2007.

[3] B. Kroposhi. T. Basso, C. Pink, and R. Deblasio, "Microgrid standatrd and technology development," Power Engineering Society General Meeting, 2007.

[4] R. B. Martinez-cid, "Renewable-driven microgrids in islanded communities," Thesis in University of Puerto Rico Mayagüez Campus, 2009.

[5] A. K. Basu, A. Bhattacharya, S. P. Chowdhury, S. Chowdhury, and P. A. Crossley, "Reliability study of a microgrid system with optimal size and placement of DER," CIRED Smart Grid for Distribution, 2008.

[6] S. Diaf, M. Belhamel, M. Haddadi, and A. Louche, "Technical and economic assessment of hybrid photovoltaic/wind system wuth battery storage in corsica island," Energy Policy, vol. 36, pp. 743-754, 2008.

[7] J. Kennedy and R. C. Eberhurt, "Particle swarm optimization," International Conference on Neutral Network(ICNN), vol. 14,1995.

[8] S. M. Hakimi and S. M. M. Tafreshi, "Unit sizing of a stand-alone hybrid power system using particle swarm optimization," International Conference on Automation and Logistics(ICAL), pp. 3107-12, 2007.

[9] F. A. Mohamed and H. N. Kiovo, "System modelling and online management of microgrid using mesh adaptive direct search," Electrical Power and Energy Systems, vol. 32, pp. 398-407, 2010.

[10] F. A. Mohamed and H. N. Kiovo, "Online management of microgrid with battery storage using multiobjective optimization," International Conference on Power Engineering, Energy and Electrical Drives(POWERENG), pp. 231-236, 2007.

[11] N. Phungpornitah, W. Prommee, S. Tia, and W. Phuangporpitah, "Study of particle swarm technique for renewable energy power systems," International Conference on Energy and Sustainable Development(ESD), Thailand, 2010.

[12] P. S. Georgilakis and Y. A. Katsigiannis, "Reliability and economic evaluation of small automonous power systems containing renewable energy sources," Renewable Energy, vol. 34, pp. 66-70, 2009.

[13] L. Soder, "Reserve margin planning in a wind-hydro-thermal power system," IEEE Trans. Power Syst., vol. 8, no. 2, pp. 564-571, May 1993.

[14] K. Methaprayoon and C.Yingvivatanapong, "An integration of ANN wind power estimation into unit commitment considering the forecasting uncertainty," IEEE Transactions on Industry Applications, vol. 43, no. 6, November/December 2007. 